\title{
16 Intermediality and social media
}

\author{
Signe Kjar Jensen, Nafiseh Mousavi and Emma \\ Tornborg
}

It is probably just a matter of the blink of an eye for you to capture an Instaworthy image or video of an enjoyable moment, combine it with a suitable caption and post it on Instagram, punctuating the caption with hashtags that connect your post to a pool of other images and notes, or to sign into a location to connect to a physical spot outside your phone. No wonder your friends use emojis to react to your post the moment it is aired: heart-eyed, laughing little creatures that speak words. And a year later, when you are reminded by the app about your long-gone memory-image, how about turning it into a short-lived story, maybe flavouring it with another layer of words, emojis or GIFs, and posting it at the top of the interface for 24 hours of glimpses and reactions?

This is such an easy, almost automatic task to do and yet - now that you are well acquainted with the intermedial toolbox - you understand the level of intermedial literacy and intermedial skills that go into it! Several basic media and semiotic modes are combined and integrated: still or moving images, voice, sound, written words, hashtags, emojis and frames; and one media product is transmediated into another with different temporal and semiotic arrangements. This is only one of the many different intermedial navigations that we engage with in our everyday life across social media, be it Facebook, Instagram, YouTube, Twitter or numerous other platforms.

It wouldn't be an exaggeration to say that a considerable part of e-literacy, the knowledge and skills used to navigate the internet, is indeed intermedial literacy. But intermediality is not just latent knowledge you happen to have without knowing what forms your e-navigations. A systematized knowledge of intermedial and multimodal relations becomes especially important when social media become the subject of analysis and research. In addition to being studied in media and communication studies, social media have been a hot topic and a popular field of observation in disciplines as diverse as public relations, ethnography, psychology, digital humanities, and many more. The ability to grasp and analyse complex intermedial relations would be a prerequisite to understanding processes of meaning-making across social media as communication is increasingly hybridized and diversified for users of these platforms.

DOI: $10.4324 / 9781003174288-19$ 
In this chapter we will provide you with examples of basic analyses of macro and micro levels of intermediality in social media: YouTube entertainment, an example of a multi-layered social media practice, and GIFs, which derive from other media and migrate across different platforms on the internet. Before delving into these cases, let's begin by taking a general look at social media through an intermedial lens.

We all have an idea of what the term 'social media' is referring to. It probably ignites in our minds an image of the navy-blue Facebook logo or the lighter blue of Twitter's or some other iconic, globally used social network: Tumblr, WeChat, Instagram, Weibo, TikTok, you name it! But how can we actually define social media? What is it that is social about it and differentiates it from other media? How can we describe social media from an intermedial point of view?

Carr and Hayes, two communication and social media scholars, offer the following quite comprehensive and interesting explication of social media:

Social media are Internet-based channels that allow users to opportunistically interact and selectively self-present, either in real-time or asynchronously, with both broad and narrow audiences who derive value from user-generated content and the perception of interaction with others.

(Carr and Hayes 2015, p. 50; our emphasis)

With this definition, they distinguish social media from both traditional media - which is not interactive or internet-based - and other new media, such as email and messaging apps that are not sufficiently social. Indeed, what is social about social media is the 'multi-directionality of communication flow' or a phenomenon formulated as 'masspersonal communication' by O'Sullivan and Carr in another article (O'Sullivan and Carr 2018, p. 1161). The notion of masspersonal communication refers to the way in which communication is in a one-to-one, one-to-many, many-to-many and many-to-one form on social media. The idea behind this concept is that we should dismiss the dichotomy between mass communication as a one-to-many communication performed by mass media as opposed to interpersonal communication defined as a two-way, one-to-one form of communication. Instead, we should understand communication in social media as consisting of people simultaneously engaging in mass and interpersonal communication. Rather than being either interpersonal or mass communication, masspersonal communication differentiates across a scale and is determined by its level of 'accessibility' and 'personalization': a public post on Facebook with no specified audience is more accessible and impersonalized, while a personal tweet in a private Twitter account which directly addresses the account-holders' followers is less accessible and more personalized; however, neither of the two can be categorized as solely mass or solely interpersonal communication.

This also links to the importance of (a perception of) interaction on social media. Our interactions on social media are shaped and determined by 
algorithms. These interactions can happen in real time (live-streaming on Facebook, Instagram or YouTube and receiving live comments and reactions) or asynchronously (commenting on a friend's post from yesterday). Moreover, we do not only interact with other people but also increasingly with various types of bots, in such a way that it is not always easy to distinguish between human and nonhuman interaction on social media.

Using social media is closely tied to the developments of mobile communication. As Rasmus Helles (2013) argues, 'the central affordance of mobile phones is not the mobility of the device per se, but rather the fact that the user becomes a mobile terminus for mediated communicative interaction across the various contexts of daily life' (p. 14). Social media are accessed through a varied set of electronic technical media of display like laptops, smartphones, tablets, smartwatches, etc. These devices are generally portable and have made media use less location-bound than ever.

Accordingly, the material dimension of social media can be formulated as an integration between physicality (of the devices) and digitality (of software, apps, etc.). Although there is a common tendency to talk about the virtual versus the real world when we are discussing social media, or the web in general, it is becoming almost impossible to detach online life from offline life. Scholars such as Nathan Jurgenson believe that although the two spheres are distinct, we should avoid 'digital dualism' or the virtual vs real dichotomy. Instead, he suggests considering social media and social media practice as 'implosion[s] of atoms and bits':

The physicality of atoms, the structures of the social world and offline identities 'interpenetrate' the online. Simultaneously, the properties of the digital also implode into the offline, be it through the ubiquity of webconnected electronic gadgets in our world and on our bodies or through the way digitality interpenetrates the way we understand and make meaning of the world around us.

(Jurgenson 2012, p. 86)

In this way, social media follow us via our mobile devices and frequently pop up in our everyday practices in a shifting and fluid spatiotemporal frame. They engage our touch, hearing and sight and make all categories of semiotic relations work: the iconic value of photos and emojis, the symbolic value of words, signs and hashtags, and the indexical value of location markers, to name a few basic ones among many. The high level of hybridity and mixedness in social media is an outcome of the constant mixing, coexistence and integration of various basic media texts, moving and still images, sound-specific and more social-media, elements such as hashtags and locations, on various platforms:

the way we present ourselves to our online audiences is no longer only by textual and visual cues such as status messages, photos, or videos but also through geocoded digital traces, geographical data visualizations, and maps of individual patterns of mobility.

(Schwartz and Halegoua 2015, p. 1644) 
Apart from media combination and integration, even the two aspects of media transformation, transmediation and representation, are also persistent intermedial processes in social media practice as content creation. As you will see in the case studies, other media are engaged with in the form of quotations, framings, recycling, etc. in the everyday social media practices of entertainment, education and self-representation. Online fan culture has provided opportunities for people to transform their favourite films, novels and comics and put their own trace on them. Even more traditional ways of media consumption such as reading a book or watching a film have been reframed on platforms like Letterboxd and Goodreads, where the practice of watching or reading obtains another interactive layer for users, who are able to respond to the media products in a way that has been further legitimized and made even more systematic.

Social media provide an exciting scene where we can put our intermedial toolbox to use. They are not only a new type of media but offer a new understanding of mediation in which life and media are intertwined more than ever. This new notion and experience are best explained by what Kember and Zylinska (2012) suggest is 'the vitality' or 'lifeness' of media, 'that is, the possibility of the emergence of forms always new, or its potentiality to generate unprecedented connections and unexpected events' (p. xvii). Following this brief glimpse at social media and its intermedial dimension, we will now take a look at our two cases of applying the intermedial perspective of analysis to YouTube entertainment and GIFs.

\section{Media transformation on YouTube: Social media entertainment as an intermedial practice}

YouTube might best be described as a 'platform'. ${ }^{1}$ It is a website that enables 'professional' as well as 'amateur' media producers, and all those in between, a space in which to share and distribute video material in a variety of different forms and genres. This platform allows for both relatively 'traditional' video content, but also new types of media, which build on pre-existing material and media genres, for example, 'honest trailers', 'react videos' and 'Let's Play videos'. YouTube thus enables, and perhaps even encourages, the distribution of a range of different practices of combining and transforming material, that is, the distribution of different intermedial practices. Because the videos themselves share the same basic media modes as traditional film (cf. Chapter 2), many consider the innovative aspects of the platform to be the inherent possibilities for 'amateurs' to upload and distribute their own productions within a social community, creating an open and social practice that is in opposition to the closed processes of the traditional media of broadcasting companies and film studios. In this respect, YouTube has also often been hailed for its democratic potential, a potential which, however, exists in tension with YouTube's still more commercial profiling (see Box 16.1).

It can be hard to draw a distinct line between 'professionals' and 'amateurs' in the context of social media. On the one hand, there is no doubt that a TV 
channel, such as NBC, uploading content is professional and that a teenager uploading videos from his or her bedroom is an amateur, but what about Casey Neistat, who, besides being a vlogger, is also a professional film-maker? And what about Felix Kjellberg (b. 1989), aka, PewDiePie? PewDiePie has no official degree in media production, but he still decided to pursue a YouTube career as an alternative to going to university and making a foundation for a more 'traditional' career. At the time of writing this chapter, towards the end of 2020, PewDiePie is one of the most famous YouTubers, and he makes millions of dollars each year from his YouTube videos, in which he plays video games or talks about internet memes. PewDiePie is a professional in one sense of the term because he makes YouTube videos for a living, but at the same time, he has not been professionally trained as a media producer (although he is undoubtedly highly skilled in digital editing techniques and employs people to help with media production) and he produces a type of content that many people would still associate with 'amateur' content. In this chapter, we focus solely on the type of content that is created by individuals or groups located outside the traditional media companies. We discuss how to understand this social practice of content production within an intermedial framework, and lastly, we provide a brief analysis of how PewDiePie engages with his content and viewers in his Let's Play Minecraft videos.

\section{Box 16.1 YouTube and the tension between democratization and commercialization}

In contrast with traditional media such as film and television, having a platform for media-sharing and consumption implies an ideology of equal access and opportunity for everybody, and YouTube has often been thought of as a democratization of media distribution and as a hub where individuals can express and share their opinions within a larger community. The democratizing and equalizing potential of YouTube, and other platforms, has also been critiqued and problematized in recent years (see, for example, Allmer (2015), Burgess and Green (2009), Graham and Dutton (2019), Snickars and Vonderau (2009) and van Dijck (2013)) not least because of its increasing commercialization and professionalization. YouTube's guidelines and selective algorithms, which ultimately exercise control over what kinds of videos are being uploaded and which videos are shown to users, also problematize this democratic ideology. As a consequence, YouTube still allows everyone with access to a computer and an internet connection to upload content, but it does not allow everyone's content to be distributed to the wider population. This both entails that not everyone has equal access to be 'heard', but it also causes problems with 'filter bubbles' and 'fake news'. YouTube and other social media platforms are also being increasingly problematized in news media and popular culture, for example, in The New York Times podcast series 'Rabbit Hole' (Roose 2020). 


\section{Characteristics and conventions of 'social media entertainment': The qualifying aspects}

We will use the term 'social media entertainment', as suggested by Craig and Cunningham (2019, p. 4-5), to refer to a range of potentially profitable but non-traditional media content on YouTube. According to Cunningham and Craig's definition, social media entertainment is characterized by conventions of a high level of audience interaction, a sense of authenticity regarding the content creator, an appeal to community-building and, lastly, by being distributed in a 'commercializing space' (Craig and Cunningham 2019, p. 149), by which the authors mean the whole culture of commercialization and professionalization around this content. As we take an intermedial approach in this book, we wish to add one dimension to this characterization, namely the notion that social media entertainment is very often characterized by an extreme level of transmediation of pre-existing media content together with the representation of 'old' media types and genres in a new context. This type of transmediation might metaphorically be described as a recycling of content and genres to create something which is new and unique to social media entertainment.

\section{YouTube as a hub for an interactive, social community}

What formally differentiates YouTube videos from other types of film is the potential for interaction and communication between different parties: 1) between the producer and the audiences, 2) between different producers, and 3) between individual audiences of the videos. All of this interaction is afforded through the platform, and despite the very small number of people actively engaged on YouTube through uploading or commenting compared with the number of users on the site (cf. Snickars and Vonderau 2009, p. 12), this interactive feature has been part of shaping the content on YouTube, most notably, perhaps, through vlogs. This has created an affordance for content creators to explicitly address and encourage interactivity and community-building and has also created a higher demand for 'authentic' and visible creators.

When entering into any kind of medial analysis of YouTube content, it thus becomes relevant to ask whether it is the video itself that is the real content or whether the video has to be analyzed in the context of the larger framework of sharing, commenting and responding on the YouTube platform. When viewers comment on a video, they can be seen to transform the video into something new, making it a topic in a discussion forum rather than 'just' a video, as they evaluate and potentially negotiate and co-create meaning around what they have just seen. Sometimes, the content creator will even participate in these discussions or respond to comments in a follow-up video, further strengthening the sense of interactivity, community and co-creation. These interactions are all part of a chain that can be considered in the light of an intermedial transformation, as the meaning around the video develops through new comments and (video) 
reactions. In our case study of PewDiePie later in this chapter, we concentrate on PewDiePie's ways of encouraging these interactions, as we focus on 'textual' strategies in the videos themselves, and we therefore only refer sparingly to his followers. This is an analytic choice on our part, and other choices regarding the balance between the inputs by the content creator and his or her audiences can be a legitimate strategy, depending on your research interest and theoretical framework. For an example of a study with a more socially oriented focus that concentrates on what happens in the chain of comments and reactions, see Ruth Page's (2018) Narratives Online.

\section{Media transformation on YouTube}

One of the most popular video types on YouTube is the vlog, but within the form of the 'vlog', many different formats are possible, and 'vlog' can be hard to define clearly, as we discuss in Box 16.2. Taking a glance at a list of 12 recommended vlogs in an online article by social media manager Rob Nightingale (2017) reveals YouTube videos that are based on a range of antecedents. Most obvious is perhaps the older brother, the blog, which has its roots in written diaries and oral confessions, but antecedents in the form of qualified media such as video games, films and home videos are also evident. It is, moreover, interesting to note the number of qualified media types and genres which are being transmediated through vlogs. That is, genres that were initially mediated through writing technologies and later by video are now being taken up by internet platforms, and both basic and qualified media types from before the invention of the internet are being represented through social media entertainment. These genres are travel logs, educational content and news coverage, and it is evident from the list of vlogs recommended in the article by Nightingale (2017) that they cover everything from personal stories to climateaware travel and videos aimed at informing viewers about psychic illness or politics. Consequently, what characterizes these particular YouTube videos, and what seems to be a general tendency for a lot of social media entertainment, is that they transform of 'old' media content, types or genres into social media, taking on the qualifying aspects of social media entertainment in addition to the pre-existent characteristics. In a way, what social media entertainment does, is to creatively recycle pre-existing media content, types and genres in a new context.

This is very explicit when pre-existing material is used to make a new product, which we see with 'honest trailers', and sometimes the practice of recycling is more implicit in the form of media representations of older types of media, such as the blog. Thus, the transformation happening on YouTube, and similar platforms, means that 'old' qualified media types are now being mediated by social platforms, which encourages a sense of interactivity and community, as discussed above, but also of authenticity (which we will turn to next), which did not exist in the original form of the 'recycled' material. 
When we use the metaphor of 'recycling' to describe these transformation processes involving both transmediation and media representations (see Chapters 9 and 10), it is to highlight that social media entertainment often has a much more extensive and explicit reuse of media content and/or qualified media characteristics than what we usually see in 'traditional' fields such as literature and film. Let's Play videos are, for example, much more than 'just' an adaptation or representation of a gameplay, as entire sections of gameplay are 'quoted' at length in Let's Play videos and become the topic of the videos. Likewise, the 'travel vlog' is not just representing travel logs and blogs but fully appropriating these genres in a social media entertainment format.

These kinds of creative uses and recombinations of existing content, which we see in social media entertainment, are also studied in the growing discipline of 'remix studies', taking their name from the popular musical practice. As remix studies constitute a distinct, albeit related, discipline to intermediality studies, we will not discuss this concept further here, but the interested reader is encouraged to consult Navas, Gallagher and Burrough (2014, 2021).

\section{Box 16.2 What is a vlog?}

The word vlog is a contraction of the words video and blog. The concept thus names an intermedial combination of the qualified medium of blog with the basic medium of video (we refer to video as a basic medium here because it is not the qualified dimensions of film that are relevant but the pure resource of video recording). Another way to look at this is to see the vlog as a transformation of the blog into an audiovisual form - a transformation that adds the affordance of emphasizing the content creator's face and voice, adding to the authenticity dimension, which is so characteristic of social media entertainment.

With regard to both form and content, the term vlog has been used ambiguously and can refer to the style of the earliest videos uploaded to YouTube, to videos on social media which more generally showcase personal content, or to any video which is produced by individuals or groups located outside the traditional media. Most often, however, vlog refers to a video in which a content creator speaks directly to the camera, making a seemingly personal, sincere, authentic and direct address to the followers of a channel. The camera tends to be used as a 'window' through which the content creator can speak to the audience, rather than making the audience feel like an 'observer', as in traditional media content.

\section{Authenticity and bodily presence in opposition to traditional media}

One of the primary ways in which these videos succeed in terms of their social transformation, and authenticity, is by being produced by seemingly 'ordinary' people located outside the traditional media industries: content creators who 
use themselves, their own bodies, voices, lives, and interests to communicate in a space where 'talking back' is allowed (see also Craig and Cunningham 2019, p. 148-83). Even though the most popular YouTubers are indeed 'professionals' who make a living from their social media content and who hire trained personnel to assist with editing, marketing, legal concerns, etc., they still put themselves in front of the camera and speak to their audiences as if they were friends. As such, a specific type of authenticity, which is created through a perceived distance to traditional media and through an acknowledgement of and direct address to an audience, as well as through the bodily presence of the main content creator(s), seems to be a convention of social media entertainment.

The concept of authenticity always has to do with the implied representation of what is not present or cannot be seen. This is, e.g., also the case when a media product conveys an authentic representation of the 'real' world (i.e., the nonmediated world) and when personal communication involves authentic outward expressions of invisible inner feelings. When new media appear, the relation between what can be constructed by mediated authenticity and what are signs of personal authenticity has to be renegotiated and can easily be mixed up (Enli 2015). The short history of YouTube has revealed instances where YouTubers have gained large followings from uploading seemingly personal stories, which have later been accused of being scripted. The most extreme case of this sort was probably when the famous YouTuber LonelyGirl15 was discovered to be an actor in 2006 (see Burgess and Green 2009 for a discussion of this 'fake' vlogger). Even when the stories are not scripted, however, a YouTuber always chooses what we see and what we don't see and what types of glimpses we get into their personal lives. Therefore, the people we see on YouTube can be considered to be constructed media personas, i.e. what we see is a specific version of a person and not the whole truth. That is why we prefer to talk about authenticity with regard to social media personas rather than with regard to 'real' people. Ultimately, we can only analyze and discuss a YouTuber based on what they have made publicly available (the persona) and not who they are outside social media.

\section{Box 16.3 Authenticity}

When we speak of authenticity, this concept always involves both the notion of immediacy and construction/staging. Authenticity refers to a kind of representation that is constructed, staged or enacted in a way so that it conveys an experience of immediacy and presence - a kind of 'natural enactment' (van Alphen, Bal and Smith 2009) - a representation that is truthful in respect to different phenomena in different contexts (see Chapter 13).

In the case of historical and artistic objects, authenticity is perceived as a property of the material and stands for the object's 'originality', or unbroken connection with something that is perceived as original. In interpersonal communication, a personal authenticity, in the sense of sincerity, refers to outward expressions that are consistent with inner feelings, convictions and involves the assurance that the speaker stays true to oneself. 
In media contexts, authenticity involves a focus upon how the experience of immediacy is constructed by media. The accusation of inauthenticity is a common feature of media criticism and derives from the fact that many media products are fundamentally materially inauthentic in relation to what they mediate. Still, a theatre play, a film, a novel, a vlog can be perceived as a truthful representation of real-life experience. Gunn Enli (2015) lists a number of strategies such as spontaneity, immediacy, the use of confessions, ordinariness, ambivalence and imperfection that all function as authenticity markers and help to construct mediated authenticity.

In the authenticity discourse of social media entertainment, YouTubers pose themselves as an alternative to traditional media. Traditional media are perceived as driven by commercial interests, presenting fictional experiences and as not being open to audience involvement. In contrast, the norm for creators of social media entertainment involves showing a genuine, personal interest in their own content and community, as well as using real feelings and experiences as background for their videos. However, when a certain type of personal behaviour becomes necessary to gain success, then this behaviour can be staged to gain popularity.

In Craig and Cunningham's review of authenticity as a concept in cultural studies, there is an emphasis on the problematic relation between authenticity and commercial interests, also explored in business studies (Gilmore and Pine 2007), which is relevant when approaching authenticity in social media entertainment. There arises a tension between the promise of an authentic personal behaviour on the one hand and authenticity as a commercial selling point on the other (for a broader discussion of authenticity on social media generally and in relation to PewDiePie, see Craig and Cunningham 2019, Chapter 4).

\section{Summing up social media entertainment}

Based on the previous discussion, one could argue that social media entertainment is a specific type of qualified medium, characterized by the conventions of (1) extreme levels of transmediation (extreme compared to 'traditional' media) in the form of a recycling of content, genres and media types, (2) interactivity, (3) community, (4) authenticity and (5) by being distributed on a social media platform. It is a qualified medium that is stratified into several genres or submedia, however, such as Let's Play videos and DIY tutorials.

Social media entertainment even has a unique history of developing these conventions through its short history. Although social media entertainment does not belong exclusively to YouTube, it is interesting that these conventions can all be traced back to the very first YouTube video, 'Me at the Zoo', which was uploaded by one of YouTube's founders, Jawed Karim, in 2005 (Jawed 2005). The video is only 18 seconds long and shows Karim at the zoo in front of some elephants (see the still in Figure 16.1). Karim is mostly speaking 
directly to the camera, saying (this and all following transcriptions of speech in videos have been made by the chapter authors):

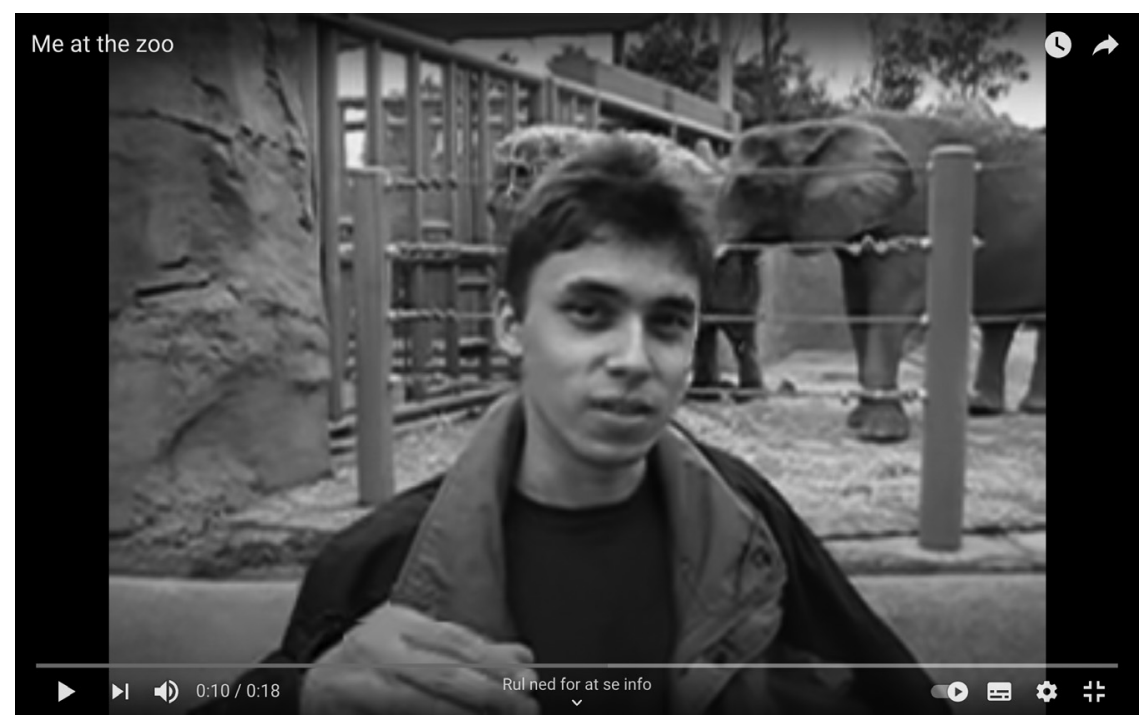

Figure 16.1 Screenshot of the first YouTube video, 'Me at the Zoo', posted by YouTube co-founder, Jawed Karim, in 2005.

Alright, so here we are [looks left] in front of the [gazes into the camera again] ah ... elephants. [looks over his shoulder to the elephants and back to the camera]. Mhmm the cool [emphasizes with a hand gesture] thing about these guys is that, is that [sic] they have really, really, really [emphasizes with rhythmic movements of hand on each 'really'] long, uhm, trunks [illustrates with hand gesture]. And that's cool [looks over his left shoulder to the elephants again and back]. And that's pretty much all there is to say.

The quotation from the video shown in Figure 16.1 is an example of a simple multimodal transcription that transcribes the words verbatim along with simple gaze and hand gesture notations. Our multimodal transcription helps to make it clearer how Karim relates to the camera and how he uses his body when he is conveying his personal experience of being at the zoo. His language and body are directed at the audience behind the camera, except for a few glances he makes towards the elephants (perhaps showing that he is a bit shy in front of the camera), and his language and body are, unlike an actor in a film, unpolished and natural; there are spontaneous pauses and gestures. This unpolished address to the audience creates a sense of authenticity, unscripted personal expression and invites community-building and interaction. The video represents structures familiar from the blog format and perhaps also news 
reporting because of how Karim is placed in relation to the elephants and the camera, as if he is 'reporting' on the elephants at the zoo, a media practice associated with authenticity and trustworthiness in relation to a journalist. These patterns that refer to conventions of blogging and news reporting thus help create an impression of personal authenticity.

To sum up, social media entertainment can be described as a qualified medium that transforms previously existing media types and genres, mainly diaries, blogs and home videos, into audiovisual content on a social platform. Furthermore, social media entertainment stages the body, voice and personality, or persona, of a content creator outside the traditional media and acknowledges, or even addresses, the social community directly. One approach to the intermedial analysis of YouTube videos would therefore be to look for ways in which a video establishes these dimensions of transmediation, authenticity, interactivity and community. Questions to ask yourself are: which media types or pre-existing content, e.g. narratives, images or structural patterns, are being transmediated and represented? What kind of meaning potential is being transferred along with the recycled material, media type or genre? Are practices from different 'old' media types combined (e.g. if Karim had inserted animation or music into his report on the elephants)? How are the content creator's body language and voice quality used and combined with the images? How is the video being interpreted and negotiated in the comments, and does the content creator react to comments, thereby allowing the followers to influence the content? We explore these questions in a brief example analysis by taking a closer look at the Let's Play genre and how the YouTuber PewDiePie engages with the social media entertainment dimensions and with his audiences.

\section{PewDiePie plays Minecraft, and 37,000,000 watch}

PewDiePie is a Swedish gamer and YouTuber whose real name is Felix Kjellberg. He started his career in 2010, and in 2019 he hit 100 million subscribers. PewDiePie's channel was for several years the largest channel on YouTube (from late 2013 to early 2019 - briefly surpassed by YouTube Spotlight in 2013), and as such, he has been widely influential. He is also one of the most controversial personas on YouTube, however, with several scandals in his wake, making people either love him or hate him (see, for example, BBC Newsbeat 2019). The main content of PewDiePie's channel (PewDiePie n.d.) is Let's Play videos, but he has also done a substantial amount of other types of social media entertainment, such as react videos, rants about current trends and updates on his personal life. In this section, we briefly discuss PewDiePie's recent Let's Play Minecraft series (uploaded 21 June 2019-28 April 2020) (PewDiePie 2019g) consisting of 45 publicly available videos, which we will refer to as 'episodes' in the following analysis because PewDiePie himself refers to the individual videos as episodes in a series.

'Let's Play' refers to a social media entertainment genre in which a gamer plays video games while talking to his audiences and commenting on the game, and the gamer's face and upper body are often visible in the video along with 
the gameplay. Through the gamer's comments, Let's Play contains an address to the audiences and showcases the personality (or persona) of a gamer; there is also a focus on the gamer's face, which is filmed up close - all typical tools of social media entertainment. Let's Play is thus also an obvious case of media transformation, where a video game is transferred into a new context and thus transformed into social media entertainment, and it can be considered both a transformation of the videogame and also a combination of video games with the basic medium of video and the qualified conventions of social media entertainment (see also Chapters 5 and 17).

Let's Play is one of the most popular video types on YouTube, but platforms dedicated to live-streaming, particularly of gameplay, also exist, e.g. Twitch, on which PewDiePie also has an account. The difference being that Twitch is used for live-streaming sessions, and YouTube, at the time of writing, mainly for pre-recorded material, which, unlike the live streams, might be substantially edited, as we will see with the analysis of PewDiePie's Minecraft videos.

One of the absolute strengths of PewDiePie's videos is his very strong invitation to interact and build communities. Not only does he speak directly to his followers as if they were friends (referring to them as 'bitches', 'gamers', 'bros' or '9-year olds'), but he also named his Minecraft world 'Broland' in reference to his followers, allows them to have a direct influence on the gameplay and responds to their comments. In the opening of 'Im actually having... FUN? In MINECRAFT (hacked) - Part 2', for example, PewDiePie addresses comments which his followers posted for the first video in the Minecraft series:

Broland continues. You guys have been making fun of me in the comments, don't think I don't read those [waving a pointed finger at the camera], saying I don't know how to play a game, I don't know how to make Minecraft. Me, I'm a veteran okay? I was born to play Minecraft. I've played Minecraft before you [points at the camera] were born. Okay?

(PewDiePie 2019d [00:00:07])

Here we can see that the audience is clearly being addressed by PewDiePie, who is speaking into and gesturing towards the camera. These words also speak to how he creates authenticity by 'staging' a particular persona. The lines here contain a classic, self-ironic joke about PewDiePie being a veteran and basically a master of Minecraft, and the lines are said in a light-hearted way in PewDiePie's characteristic, exaggerated, Swedish accent. Even though he is Swedish, the exaggerated accent is something that he adds on and off for comic effect, and it is part of his unique YouTube persona to play on this Swedishness. This is perhaps most obvious when PewDiePie decorates his buildings in Minecraft with the Swedish flag, when he refers to blue birds as 'Ikea birds', and when he decides to build a huge 'Ikea tower' and a giant meatball.

Even more important to this persona is when he talks openly about himself as a private person. On these occasions, the comedic act is dropped, and PewDiePie normally uses a more calm and sincere tone of voice. He does this 
several times during the series, not least at the beginning of episode 29 (PewDiePie 2019e), when he shares some of his actual wedding photos. He also talks to his audiences about the very recent wedding and his feelings about it later in the episode, letting his followers get a glimpse into his personal life. This build-up of a credible and likeable YouTube persona is an important strategy for creating authenticity and encouraging community, as it invites the audiences to come a little closer, not just to PewDiePie but to the person behind PewDiePie, Felix Kjellberg. It is important to remember, however, that we can't tell how well this self-ironic Swedish PewDiePie corresponds to the 'real' Felix Kjellberg - to the way he would speak and act in private. But by sharing private thoughts and emotions and by showing seemingly spontaneous thought processes and reactions while playing, PewDiePie's persona comes to seem real, as if he is a close friend of his audiences and is on equal terms with them.

Coming back to the interactivity and community-building, PewDiePie also responds to advice and suggestions from his followers, sometimes with more success than others. An example of his followers managing to 'troll' PewDiePie is when it was suggested that he should sleep in Nether (a hellish subworld of Minecraft), which he attempts to do in episode 5 'I slept in the Nether in Minecraft':

Okay Jörgen [PewDiePie's first Minecraft horse] wish me good luck, we're going to the Nether. 'Cause everyone said there is a secret achievement [zoom in and enlargement of PewDiePie's face] if you sleep in the Nether [cuts back to small visual of PewDiePie in the corner of the screen]. Why would anyone do that? Oh God this place is SO creepy dude. Why on earth would I sleep here? This is awful. Alright fine, we'll make a little Nether realm house. How about that? It's gonna be so cute. Oh my God I am scared [laughing]. Alright good night gamer - AAHHHHH [PewDiePie screams as his character dies, and the screen shows 'sub2pewdiepie12 was killed by (Intentional Game Design)'].

(PewDiePie 2019c [00:04:43])

PewDiePie was thus tricked into killing himself in the game. After this happens, PewDiePie goes silent for a few seconds, sighs, and then a black and white, highly transparent recording of his face is superimposed on the screen, taking up almost half of the space. The brightness of the colours of the gameplay is turned down, and melancholic, simple piano music is played in the background. PewDiePie continues: 'My own audience, my own supporters. Can you believe this?' (PewDiePie 2019c [00:05:19]).

Here, PewDiePie again addresses his audience directly, and he also takes the chance to use visual and auditive editing techniques familiar from film and TV to create a somewhat ironic, emotional and comic effect. PewDiePie's voice, face and overall reactions become part of a joke but also give the impression that we are seeing PewDiePie's genuine emotional responses. This is just one example of PewDiePie's heavy use of editing techniques in his videos, which 
points to a tension between the seemingly 'authentic' gameplay and the 'finished' YouTube video. When this tension still works in the context of PewDiePie's authenticity, it is because the edited media product emphasizes PewDiePie's emotional reactions, self-irony and humour.

These editing techniques and references to film and TV are not only added as an authorial comment on the gameplay or as response to seemingly bad advice from PewDiePie's followers (which is allowed through the social interaction) but also to create a narrative coherence across the episodes. Towards the end of the series, in the final moments of 'Married in Minecraft Epicly - Part 29' (PewDiePie 2019e), one of PewDiePie's pets, a pig called Peepeepoopoo, nudges him into a portal, behind which the dreaded Ender Dragon is waiting (the final boss and biggest enemy in Minecraft). The episode ends abruptly on this 'cliff-hanger'. This ending is replayed at the start of episode 30, 'I challenge the Ender Dragon in Minecraft (Ending)' (PewDiePie 2019a), representing structural patterns familiar from TV series to create drama, coherence and audience engagement across episodes. As the replay ends and the 'real' episode begins, PewDiePie delivers a dramatic monologue, backed up by solemn music and sound editing, which adds a little bit of reverb to selected sentences of his speech:

My own ... friend, my best friend in the whole world. Peepeepoopoo. Peepeepoopoo. He betrayed me! Oh my God. Peepeepoopoo! I'll get you for this! I'll get you for this one day [PewDiePie rubs his eyes, as if in distress]. He pushed me in. Surely it must have been a mistake? There's no way Peepeepoopoo would deliberately betray me? Oh God.

(PewDiePie 2019a [00:00:31])

Here, the difference between 'PewDiePie as authentic Felix Kjellberg' and 'PewDiePie as a persona' becomes particularly blurred, as PewDiePie is 'acting' as his Minecraft character but in a way that is coherent with his YouTube persona, and he seems to express genuine feelings of betrayal and hurt.

Peepeepoopoo is quickly forgiven, though, and when he dies later in the same episode, we get to see an edited montage sequence, showing the best moments with Peepeepoopoo along with melancholic piano music (PewDiePie 2019a [00:12.48]) (a stable technique that PewDiePie uses every time a Minecraft pet dies). Towards the end of this montage, the music changes into a more active and dark sound, reminiscent of action films when a hero is getting ready for battle. This music plays while we see an edited gameplay of PewDiePie getting ready to fight the Ender Dragon (PewDiePie 2019a [00:14:18]). Thus, the editing and choice of music here create a clear parallel between PewDiePie's Minecraft character and the trope of action heroes from film and TV.

It is clear that PewDiePie's different combinations of the gameplay with film and TV conventions have several effects: they create narrative coherence across episodes, they 'import' meaning potential through associations with emotionally charged editing techniques, conventions and character tropes, and they 
provide a base on which PewDiePie can showcase his self-ironic persona in an authentic manner.

Regarding PewDiePie's tendency to 'narrativize' his Minecraft series, he explicitly comments on this 'strategy' in episode 31, referring to the defeat of the Ender Dragon as the 'end' of the series but not the end of the gameplay videos:

So technically, for me the series is over. It ended on episode 30 [a small image of the YouTube title of the episode moves across the screen from the bottom up and back down]. I want to keep it intact that way you know, in terms of 'storytelling' [makes quotation marks with his hands] [...] The thing is, there's a lot of stuff in the game I can do [...] So basically, to explain it, the series is over, but the series continues [emphasizes and illustrates by moving his hands to opposite sites on 'basically', 'the series is over' and 'continues'].

(PewDiePie 2019b [00:02.43])

Here, PewDiePie shows a self-awareness of the story-like qualities of the previous episodes, and just the fact that PewDiePie refers to the individual Minecraft videos as 'episodes' within a series adds to this sense of narrative coherence and once again builds on a reference to the medium of TV series.

Several of PewDiePie's followers also comment on this narrativizing and 'TV-dramatic' strategy. For instance, a commentator appreciates 'story driven episodes, drenched with character and emotion' (emphasis original), while other followers perceive 'a soap opera' or a 'drama horror show' (PewDiePie 2019h, comments online).

Many more of the comments on PewDiePie's videos, however, focus on highlighting particularly funny comments PewDiePie has made, perhaps showing that the main attraction for them is PewDiePie's unique persona and sense of humour. The gameplay thus functions to provide a topic for PewDiePie to work from, but the real enjoyment for audiences of PewDiePie's Let's Play Minecraft comes from him visually reacting and verbally narrativizing his 'journey' through the game. The combination of the gameplay, references to film and TV and the unique format of social media entertainment video provides a space for PewDiePie to stage himself with acts that express his selfirony and his emotions and humour, in turn creating authenticity, interaction and community by doing so.

\section{Social media entertainment on YouTube and intermedial literacy: Concluding remarks}

As we noted in the introduction to this section, users of social media rely on an intermedial literacy in their everyday interactions with the different platforms. In this chapter, we have argued that social media entertainment on YouTube is a particular qualified medium that often takes this intermedial literacy to an 
extreme level, showcasing a high level of transmediation, or recycling, of previously existing content, media types and structural patterns familiar from other media types. Furthermore, what characterizes social media entertainment on YouTube is how the multimodal affordances of the video medium and the dialogic affordances of the social platform are used to create authenticity (particularly through the distance that exists between social media entertainment and the traditional media and by emphasizing the content creator's face and voice), interactivity (through an address and response to the audiences) and community. As such, the intermedial combination of the basic medium of video with the qualified medium of social media entertainment and different media representations becomes productive because it allows the dual focus on the content creator's bodily presence and the meaning content associated with the referenced media.

PewDiePie is an example of a YouTuber who employs a range of different tools in the way he utilizes conventions used in film music, visual editing, narrativity, discourses of authenticity, community-building and gaming. He nurtures a specific 'authentic' YouTube persona by being present in body and voice, speaking openly about his life and being self-ironic about being a Swede. $\mathrm{He}$ also encourages interaction by speaking directly to his audiences, making 'brofists' with the camera, referring to his followers as a community (e.g. as an army of 9-year-olds), and reacting to their responses. Finally, he transmediates gameplay as well as conventions from film and TV to create engaging, coherent and humoristic content.

\section{The intermediality of GIFs - How to express yourself with another face}

Most people are probably familiar with GIFs at this point. Born in 1987, and therefore four years older than the internet itself, the GIF initially functioned as a space-saving format that could be used to send colour images digitally via companies such as CompuServe (Boissoneault 2017, n.p.). In 2012, Katherine Brown argued that the GIF is 'an outdated, retro, online bitmap image format that was prevalent in the early popularization of the internet as a kitschy animation often representing flames or glitter for an email signature, the background of a website, or as an icon' (p. 6). However, in recent years, the GIF's popularity has increased enormously, and technical media such as smartphones and social media platforms such as Facebook and Twitter have facilitated the use of GIFs in text messaging, chats, posts and comment sections. The GIF is a qualified medium that is mainly used as a communicative tool in everyday digital communication. The most common type of GIF is the reaction GIF. From an intermedial perspective, there are many aspects of the GIF that can be studied: for instance, the transmediation of images but also of emotions, representation of qualified media types like film, temporal aspects of a loop, the tension between movement and stillness, the performativity of posting a GIF. In this section, we are going to discuss some of them. 


\section{Intermedial performativity}

Chiel Kattenbelt (2010) asserts that 'intermediality is very much about the staging (in the sense of conscious self-presentation to another) of media' (p. 29). This is what the GIF does. It represents - points to - its source media product, most frequently a short scene of a film, and it stages it by repeating a certain moment in an infinite loop. Hampus Hagman (2012) claims that the GIF liberates the pure movement that is inherent in film and suppressed by narrative cinema. Thus, according to Hagman, the GIF performs through one of the essential properties of its source medium film, the moving gesture: 'Posted online, another viewer recognizes the strange and altered form a (possibly) familiar moment from a film has taken, and hence becomes aware of movement as pure potential. Quite literally, it gestures to him or her' (Hagman 2012, n.p.). This is a fruitful way of regarding the performative potential of the GIF: as an estrangement that emphasizes the media characteristics of the source medium but by doing so transforms it and provides it with new properties and new meaning.

The representative aspect of the GIF is emphasized by Tolins and Samermit (2016), who investigate GIFs in text messaging. They see the reaction GIF as a kind of substitute for the sender's own gestures or expressions. When posters use a GIF to perform a reaction, they are 'borrowing' someone else's expressions and gestures and making them their own. The substituting role of reaction GIFs is essential. If online communication does not include the use of camera or microphone, we do not see the face or hear the voice of the person we are communicating with. This can easily cause misunderstandings, since body language and tone of voice are important tools that we use to get our message through. Rhetorical devices such as irony can be especially difficult to convey in writing, which everyone who has ever looked through a heated commentary section knows. To facilitate communication, different strategies have been employed over time. Twenty years ago, posters often described their

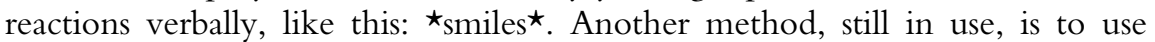
manual emojis, such as :-), when letters and punctuation form ideograms of a smiling, laughing or sad face. GIFs use iconic signs but are often combined with symbolic signs when captioned. The basic media type of moving images is used to visually represent the poster's sensations or reactions, enhancing the message and clarifying the poster's position in the communication. Tolins and Samermit (2016) argue that 'GIFs can be analysed as a novel form of embodied reenactment or demonstration [...] These GIF demonstrations are meant to be taken as the contributor's own actions' (p. 76).

However, the GIF is not a medium that only represents pre-existing content or ideas. According to Miltner and Highfield (2017), '[m]ore than just representing affect, GIFs have the capacity to augment and shape our affective performances', because 'selecting and using the GIF format is a performance in and of itself (p. 4). This relates to Brown's (2012) study of how GIFs are used to construct sexual, political and ethnic identity in online communities such as Tumblr. For example, within fandom communities, fans can create and share 
GIFs that suggest that characters that are straight according to the official description are in fact having relationships with each other that might be described as LGBTQ+. This is how fan fiction works, but using such GIFs is also a way for a poster to position themselves within a community - to construct and perform an identity, which is not necessarily identical to their IRL identity.

Hence, the GIF can be understood and studied as a performative medium because of how it turns, for example, gestures or facial expressions that are performing an emotion in one context to performing it in a completely different context. A GIF represents the poster's reaction in an exaggerated manner, since it isolates what G.E. Lessing in his essay 'Laocoon' (1766) describes as 'the pregnant moment' (or at least one of them) from the scene it derives from in the source media product (for example, short excerpts from TV series, interviews, films and home videos): facial expressions, gestures and movements that indicate strong emotions such as surprise, anger, joy, embarrassment, love, excitement, etc. The repetitive nature of the GIF underlines the sentiment it embodies. Another common feature is the zooming-in element: the GIF often only shows a section of the camera frame in the film, zooming in on the face of a person pulling a face. This zooming in is constantly repeated, which adds to the sense of exaggeration.

The GIF is meant to provoke a reaction in the responders or amuse them, and most of the time, there is no doubt what reaction the poster wants to convey, even in cases where the responders are not familiar with the source of the GIF. However, the essence of the GIF is that it transmediates another media product and knowledge about that product is important: for the poster to display cultural knowledge and cultural affinity, and for the responders to understand the full meaning of the reaction. Miltner and Highfield (2017) call the demonstration of cultural knowledge one of 'two core aspects of digital communication' (p. 3), the other being the performance of affect. For example, posting a GIF representing the obscure cult film The Room (Wiseau 2003) frames the poster as a film connoisseur and, because of the (unintentional) nonsensical nature of the film, the full meaning of the reaction can only be grasped if you have seen The Room or know a lot about it. Here the GIF functions as an intermedial hint for the already initiated. An example of GIFs strengthening the cultural affinity within, for example, a fandom is highlighted by Katharine McCain (2018). She explains how fans use GIFs to close the gaps between the original source medium (the Harry Potter book series) and the Harry Potter films. This, according to McCain, is done in three ways:

1. Using GIFs as a means of fixing apparent mistakes in the films,

2. Recreating significant, canonical scenarios that didn't make it into the films and

3. Creating new scenarios that help to continually expand the Harry Potter universe and keep the fandom alive (p. 114).

One example of an alternative plotline often explored by fans in GIFs and memes is a romantic relationship between Harry Potter and his nemesis, Draco Malfoy. 
A GIF can function without any knowledge of the source media product from both the perspective of the poster and the perspective of the audience. But it still requires knowledge about the meaning of the gesture - eye-rolling as a conventional sign for 'I can't even' - or the operational aspects that qualify the GIF - how a GIF is used, the different types of GIFs, etc.

\section{Transmediation}

One of the most important intermedial features of the GIF is its transmedial and transformative nature. All GIFs that are created from a source media product both transmediate and represent that media product, which means that they reconstruct ideas, concepts and structural characteristics of another medium (see Elleström 2014, p. 14) and at the same time they represent, that is, point to, that medium. In these processes, the source media product - the film, TV series, news programme, home video, TV show, music video, etc. - is not only reproduced but transformed, and recognizing these changes is paramount if one wants to comprehend the essence of the GIF and its intermedial character. Table 16.1 below clarifies the differences between a source media product and the GIF as the target media product. This can serve as a starting point for an analysis of transmediation that transforms fragments of a source media product into a GIF.

Where the source media product is a stable artefact and presented to an audience in a one-way, top-down type of communication, the GIF is dynamic, user-generated and in constant dialogue with its source media product, other GIFs and other media products in general. A GIF only transmediates a tiny snippet of the original narrative or communicative situation, and without the original context, the meaning of the source medium is destabilized. New meanings can be added to the snippet, and it can be used in an infinite number of new contexts: 'GIFs create new meanings in the process of exchange. Their layers accrue, bearing traces of where they have been' (McCarthy 2017, p. 113). Miltner and Highfield (2017) assert that

Table 16.1 Transmediation from a source media product to a GIF

\begin{tabular}{ll}
\hline The source media product & The target media product GIF \\
\hline One & Many \\
Complete & Fragment \\
A known originator & Usually anonymous \\
Hierarchic relation between producer and & User-generated; part of a participatory \\
audience & culture \\
One specific meaning in one specific & Many different meanings in many differ- \\
context & ent contexts \\
Progression & Repetition \\
Stable & Changeable and dynamic \\
Typically includes sound & Silent \\
\hline
\end{tabular}


[t] he meaning of a GIF changes dramatically depending on who is using it and in what context. The perpetual embedding and re-embedding of GIFs in new conversations, listicles, and coverage of different topics highlight the content's malleability as it is repeatedly appropriated.

Popular GIFs are around for years and can disappear for a while only to resurface, and this process continues.

One example of a GIF that has taken on different meanings in different contexts is one that features the bald little boy from the film The Matrix (1999) who can bend spoons with his mind, but then tells Neo: 'Do not try and bend the spoon. That's impossible. Instead, only try to realise the Truth ... there is no spoon ... Then you'll see that it is not the spoon that bends, it is only yourself (Matrix.fandom.com, n.d.). The scene is dramatic and dignified, which makes it funny to use in less serious contexts, such as in a list on BuzzFeed.com (Dunlap 2018) about 'The 17 Best and Worst Things About Having a Tall and Skinny Boyfriend', where number five is 'Finding a comfortable way to cuddle is one of the biggest challenges in your relationship'. 'There is no spoon' here means that it is difficult to 'spoon' when there is a big size difference. Natalie Brown (2017) lists '25 Hilarious April Fool's Ideas People Have Actually Tried', and number 21, called 'A Matrix-level mall prank' is illustrated by the spoon GIF:

You need at least three friends to help you and some poor stranger to play it on:

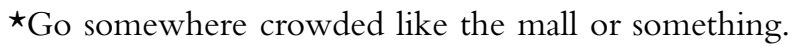

$\star$ Pick your victim.

* Spread out and follow that person around, and periodically have each person you're with pass them and say, 'Wake up', 'You're in coma', 'This is a dream'. 'None of this is real', etc.

(Brown 2017, n.p.)

In 2017, a Reddit user posted the spoon GIF with the following caption: 'HIFW [How I feel when] I Go to Bed Every Night as a Single Person' (www. reddit.com 2017). Here as well, the spoon refers to 'spooning'. As we can see, over time, the scene from the film has resurfaced online in GIF form, taking on new meanings in different contexts. Still, this GIF would not be funny if we did not know the original meaning and context of it. The contrast between the philosophical and moving scene in The Matrix and contexts involving dating, making out and pranking strangers in the mall is what makes the GIF funny. This is often the purpose and effect of GIFs and memes (here denoting captioned still images): to make fun of the source media product or the person they represent, sometimes in an affectionate manner but sometimes for example, in political contexts - not so much. Nothing is sacred to the grassroots internet culture. 
Another example of irreverent representation is what can be called the art GIF, a type of GIF that represents and perhaps, to borrow a term used by Bolter and Grusin (1999), refashions famous paintings, since it adds movement to the static artworks, thereby realizing the old dream of the moving painting (Gradinaru 2016, p. 181). In the following example, Edward Hopper's famous painting Nighthawks (1942) is transmediated into the GIF format (Useumorg 2016). The GIF is zoomed in to the couple sitting together at the diner. Close to the man's head, a notification of a new message pops up. Directly thereafter, two dialogue boxes, 'confirm' and 'ignore', appear close to the woman's head. The computer pointer clicks on the ignore box and the two boxes reappear. The GIF zooms in on the aspects of social media contact administration that lack emotional closeness and commitment. The GIF is a subtle play with the themes of loneliness and isolation that are attributed to Hopper's work and an effective way to refashion them in a social media context.

\section{Temporality and stillness}

Since a GIF is constituted of a small snippet from its source media product, and since it is repeated ad infinitum, the relation between progress and stillness is complex. Repetition is a paradoxical device, since it conveys both movement and stasis; there is movement, but it never goes beyond the depicted seconds, which provides it with a sense of stillness: 'By removing their original context and adding the perpetual repetition of a single action, they also become atemporal' (Brown 2012, p. 8). Alessandra Chiarini (2016) describes it as follows:

Made up of individual stills repeated to generate a short cyclical animation, often intermittent and potentially inexhaustible, GIF-images tend to reveal, via a series of small shocks, the paradoxical nature of the moving image which turns out to be connected on many levels to stillness.

Hampus Hagman (2012) notes that the purpose of the GIF is not to tell an unfolding story but the opposite: the purpose is to remain in the moment. Therefore, even when what is transmediated to a GIF is part of a larger narrative (such as GIFs made from films or TV series), the result of the transmediation is anti-narrative; the transfer totally changes the spatiotemporal characteristics of the source medium. Regarding art GIFs, the situation is somewhat more complicated. The source media product, the painting, is materially static, but after it is transmediated to the GIF, it contains movement. How that movement affects the source media product, the painting, depends on the temporality it conveys rather than the temporality of its interface. A painting is materially static but can depict or indicate movement in various ways, for example, by means of blurring effects, stretched out shapes, characters depicted as being in the middle of an action, etc. Take, for example, Vincent van Gogh's painting The Starry Night (1889): the sky appears to be in motion due to the spiralshaped, whirling clouds surrounding the glowing stars. GIFs made from this painting 
(and there are many) often focus on the sky, amplifying the sense of movement already inherent in the spatiotemporal modality of the painting.

A painting can also convey a specific sense of stillness and motionlessness. All still images are static in the material modality. However, still life paintings and portraits are examples of artworks that often convey a particular sense of stillness. Even Edward Hopper's paintings are often described in such terms. In these cases, the repetitive movement of the GIF can emphasize the sense of stillness already inherent in the painting, since repetition in itself is not progressive but the opposite: it halts time and hinders narrative development. Thus, as Bolter and Grusin (1999) point out, the result of the transmediation can be negotiated as reform:

We have adopted the word to express the way in which one medium is seen by our culture as reforming or improving upon another. This belief in reform is particularly strong for those who are today repurposing earlier media into digital forms.

(Bolter and Grusin 1999, p. 59)

GIFs can be studied from various perspectives, and we have here concentrated on a few of them: performativity, transmediation and temporality. These are all inherently intermedial issues. Studying GIFs from these perspectives will provide you with a deeper intermedial understanding, as well as an understanding of the complex character of the GIF.

\section{Intermediality and social media: Conclusion}

The two examples discussed demonstrate the extent to which social media are a context for the new to emerge out of the old. New media types, new media products, novel types of human communication and new spaces for interaction are created one after the other and provide us with unprecedented opportunities for action and agency. This vitality is, to a considerable extent, generated through intermedial relations and multimodal configurations.

These intermedial relations rarely exist independently but are interwoven together, as you saw in the macro level of social media entertainment and in the micro level of GIFs. Existing media types and media content are transformed into new forms through various types of transmediation and media representation and the coexistence, combination and integration of different media creates the reality of social media.

Perhaps it is possible, now more than ever, to feel the way in which media is an extension of our human bodies and minds as we experience a sense of community by regularly checking on and engaging with our favourite blogger or as we outsource our bodily and facial gestures to GIFs, which can sometimes express them better than we would ourselves ;-)! 


\section{Note}

1 For the sake of brevity, we won't go into a detailed discussion and definition of the concept of platforms here, but the interested reader is advised to consult Burgess (2015), van Dijck et al. (2018) and Gillespie (2010).

\section{Further Reading}

Berryman, R. and Kavka, M. 2018. Crying on YouTube: Vlogs, self-exposure and the productivity of negative affect. Convergence: The International Journal of Research into New Media Technologies, 24(1), pp. 85-98. doi:10.1177/1354856517736981

Burgess, J. 2015. From 'broadcast yourself to 'follow your interests': Making over social media. International Journal of Cultural Studies, 18(3), pp. 281-285. doi:10.1177/ 1367877913513684

Burwell, C. and Miller, T. 2016. Let's Play: Exploring literacy practices in an emerging videogame paratext. E-Learning and Digital Media, 13(3-4), pp. 109-125. doi:10.1177/2042753016677858

Craig, D. and Cunningham, S. 2019. Social media entertainment: The new intersection of Hollywood and Silicon Valley. New York: New York University Press.

Ferchaud, A., Grzeslo, J., Orme, S. and Lagroue, J. 2018. Parasocial attributes and YouTube personalities: Exploring content trends across the most subscribed YouTube channels. Computers in Human Behavior, 80, pp. 88-96. doi:10.1016/j.chb.2017.10.041

Gillespie, T. 2010. The politics of 'platforms'. New Media E Society, 12(3), pp. 347-364. doi:10.1177/1461444809342738

Glas, R. 2015. Vicarious play: Engaging the viewer in Let's Play videos. Empedocles: European Journal for the Philosophy of Communication, 5(1-2), pp. 81-86. doi:10.1386/ejpc.5.1-2.81_1

Hillrichs, R. 2016. Poetics of early YouTube: Production, performance, success. Academia.edu. https://www.academia.edu/27036096/Poetics_of_Early_YouTube_Produc tion_Performance_Success [Accessed 1 October 2021].

Page, R. 2018. Narratives online: Shared stories in social media. Cambridge: Cambridge University Press.

Sjöblom, M. and Hamari, J. 2017. Why do people watch others play video games? An empirical study on the motivations of Twitch users. Computers in Human Behavior, 75, pp. 985-996. doi:10.1016/j.chb.2016.10.019

Snickars, P. and Vonderau, P. eds. 2009. The YouTube reader. Stockholm: National Library of Sweden.

van Dijck, J. 2013. The culture of connectivity: A critical history of social media. New York: Oxford University Press. doi:10.1093/acprof:oso/9780199970773.001.0001 [Accessed 16 December 20].

\section{References}

\section{Introduction}

Carr, C.T. and Hayes, R.A. 2015. Social media: Defining, developing, and divining. Atlantic Journal of Communication, 23(1), pp. 46-65.

Helles, R. 2013. Mobile communication and intermediality. Mobile Media \& Communication, 1(1), pp. 14-19. 
Jurgenson, N. 2012. When atoms meet bits: Social media, the mobile web and augmented revolution. Future Internet, 4(1), pp. 83-91.

Kember, S. and Zylinska, J. 2012. Life after new media: Mediation as a vital process. Cambridge: MIT Press.

O'Sullivan, P.B and Carr, C.T. 2018. Masspersonal communication: A model bridging the mass-interpersonal divide. New Media \& Society, 20(3), pp. 1161-1180.

Schwartz, R. and Halegoua, G.R. 2015. The spatial self: Location-based identity performance on social media. New Media \& Society, 17(10), pp. 1643-1660.

\section{Media transformation on YouTube: Social media entertainment as an intermedial practice}

Allmer, T. 2015. Critical theory and social media: Between emancipation and commodification. New York: Routledge.

BBC Newsbeat. 2019. PewDiePie cancels $\$ 50,000$ donation to anti-hate group: 'I messed up'. BBC News. https://www.bbc.com/news/newsbeat-49686018 [Accessed 5 February 2021].

Bolter, J.D. and Grusin, R. 1999. Remediation: Understanding new media. Cambridge, MA; London: MIT Press.

Burgess, J. 2015. From 'broadcast yourself to 'follow your interests': Making over social media. International Journal of Cultural Studies, 18(3), pp. 281-285. doi:10.1177/ 1367877913513684

Burgess, J. and Green, J. 2009. The entrepreneurial vlogger: Participatory culture beyond the professional-amateur divide. In P. Snickars and P. Vonderau, eds., The YouTube reader (pp. 79-107). Stockholm: National Library of Sweden.

Craig, D. and Cunningham, S. 2019. Social media entertainment: The new intersection of Hollywood and Silicon Valley. New York: New York University Press.

Enli, G. (2015). Mediated authenticity: How the media constructs reality. New York: Peter Lang.

Gillespie, T. 2010. The politics of 'platforms'. New Media and Society, 12(3), pp. 347-364. doi:10.1177/1461444809342738

Gilmore, J.H. and Pine, B.J. 2007. Authenticity: What consumers really want. Boston: Harvard Business School Press.

Graham, M. and Dutton, W.H. 2019. Society and the internet: How networks of information and communication are changing our lives. Oxford: Oxford University Press.

Graham, M. and Dutton, W.H. 2019. Society and the internet: How networks of information and communication are changing our lives. Oxford: Oxford University Press.

Navas, E., Gallagher, O. and Burrough, X. 2014. The Routledge companion to remix studies. New York: Taylor \& Francis Group.

Navas, E., Gallagher, O. and Burrough, X. 2021. The Routledge handbook of digital humanities and remix studies. New York: Taylor \& Francis Group.

Nightingale, R. 2017. 12 Engaging vlogs you need to start watching today. Make Use Of. https://www.makeuseof.com/tag/vlogs-to-watch/ [Accessed 12 December 20].

Page, R. 2018. Narratives online: Shared stories in social media. Cambridge: Cambridge University Press.

Roose, K. 2020. Rabbit hole. The New York Times. https://www.nytimes.com/column/ rabbit-hole [Accessed 4 February 2021].

Snickars, P. and Vonderau, P. 2009. Introduction. In P. Snickars and P. Vonderau, eds., The YouTube reader (pp. 9-21). Stockholm: National Library of Sweden. 
van Alphen, E., Bal, M, and Smith, C.E. 2009. The rhetoric of sincerity: Cultural memory in the present. Stanford: Stanford University Press.

van Dijck, J. 2013. The culture of connectivity: A critical history of social media. New York: Oxford University Press. doi:10.1093/acprof:oso/9780199970773.001.0001

van Dijck, J., Poell, T. and de Waal, M. (2018). The platform society: Public values in a connective world. Oxford: Oxford University Press.

\section{Media referenced}

Jawed, K. 2005. Me at the zoo. https://www.youtube.com/watch?v=jNQXAC9IVRw [Accessed 30 April 2020].

PewDiePie. n.d. PewDiePie channel. https://www.youtube.com/user/PewDiePie/fea tured [Accessed 2 October 2021].

PewDiePie. 2019a. I challenge the Ender Dragon in Minecraft (Ending) - Part 30. http s://www.youtube.com/watch?v=YVxaK8WQhJo [Accessed 2 October 2021].

PewDiePie. 2019b. I raid an end city in Minecraft (Epicly) - Part 31. https://www. youtube.com $/$ watch ${ }_{\mathrm{v}}={ }_{\mathrm{oLAw}}$ EGe1zY\&list $=$ PLYH8WvNV1YEnLCzUD WueIZQXDNhqLKywk\&index=15 [Accessed 30 April 2020].

PewDiePie. 2019c. I slept in the Nether in Minecraft - Part 5. https://www.youtube. $\mathrm{com} /$ watch?v $=$ YuihlgsgNSo\&list $=$ PLYH8WvNV1YEnLCzUDWueIZQXDNhqLK ywk\&index $=41$ [Accessed 30 April 2020].

PewDiePie. 2019d. Im actually having ... FUN? In MINECRAFT (Hacked) - Part 2. https://www.youtube.com/user/PewDiePie/featured [Accessed 30 April 2020].

PewDiePie. 2019e. Married in Minecraft epicly - Part 29. https://www.youtube.com/ watch? $=$ GYpOapkr5MA\&list=PLYH8WvNV1YEnLCzUDWueIZQXDNhqLK ywk\&index=17 [Accessed 30 April 2020].

PewDiePie. 2019f. Minecraft stream REPLAY. https://dlive.tv/p/pdp+zfVewDDWR [Accessed 30 April 2020].

PewDiePie. 2019g. Minecraft the series. https://www.youtube.com/playlist?list= PLYH8WvNV1YEnLCzUDWueIZQXDNhqLKywk [Accessed 30 April 2020].

PewDiePie. 2019h. This building will change Minecraft FOREVER Minecraft - Part 34. https://www.youtube.com/watch?v=2D2vWXt1uII\&lc=UgySMbts1ZZx0mGilX Z4AaABAg [Accessed 30 April 2020].

\section{GIFs}

Boissoneault, L. 2017. A brief history of the GIF, from early internet innovation to ubiquitous relic: How an image format changed the way we communicate. Smithsonianmag.com. https://www.smithsonianmag.com/history/brief-history-gif-early-inter net-innovation-ubiquitous-relic-180963543/ [Accessed 26 May 2020].

Bolter, J.D. and Grusin, R. 1999. Remediation: Understanding new media. Cambridge, Massachusetts: MIT Press.

Brown, K. 2012. Everyday i'm tumblin': Performing online identity through reaction GIFs. Chicago: School of the Art Institute of Chicago.

Brown, N. 2017. 25 Hilarious April Fools' Ideas people have actually tried. Buzzfeed.com. https://www.buzzfeed.com/nataliebrown/ingenious-april-fools-ideas-guaranteedto-make-you-laugh [Accessed 26 May 2020]. 
Chiarini, A. 2016. The multiplicity of the moop: The dialectics of stillness and movement in the cinemagraph. In Adriano D. Aloia, Francesco Parisi, eds., Snapshot culture: The photographic experience in the post-medium age. Milano: Vita e Pensiero. https:// www.academia.edu/25013824/The_Multiplicity_of_the_Loop_The_Dialectics_of_ Stillness_and_Movement_in_the_Cinemagraph_in_SNAPSHOT_CULTURE_ THE_PHOTOGRAPHIC_EXPERIENCE_IN_THE_POST_MEDIUM_AGE_ Comunicazioni_Sociali_no_1_Gennaio_Aprile_2016 [Accessed 8 December 2020].

Dunlap, Connor 2018. The 17 best and worst things about having a skinny boyfriend. Buzzfeed.com. https://www.buzzfeed.com/connorrdunlap/things-that-will-make-a nyone-whos-dated-an-awkwardly [Accessed 11 May 2020].

Elleström, L. 2014. Media transformation: The transfer of media characteristics among media. Basingstoke; New York: Palgrave Macmillan.

Gradinaru, C. 2016. The technological expansion of sociability: Virtual communities as imagined communities. Academicus International Scientific Journal, 7(14), pp. 181-190.

Hagman, H. 2012. The digital gesture: Rediscovering cinematic movement through GIFs. Refractory: Journal of Entertainment Media. http://refractory.unimelb.edu.au/ 2012/12/29/hagman/ [Accessed 14 February 2020].

Kattenbelt, C. 2010. Intermediality in performance and as a mode of performativity. In S. Bay-Cheng, C. Kattenbelt, A. Lavender and R. Nelson, eds., Mapping intermediality in performance (pp. 29-37). Amsterdam: Amsterdam University Press.

McCain, K. 2018. Transforming Harry: The adaptation of Harry Potter in the transmedia age. Detroit: Wayne State University Press.

McCarthy, A. 2017. Visual pleasure and GIFs. In P. Hesselberth and M. Poulaki, eds., Compact cinematics: The moving image in the age of bit-sized media (pp. 113-122). New York: Bloomsbury Academic.

Miltner, K.M. and Highfield, T. 2017. Never gonna GIF you up: Analyzing the cultural significance of the animated GIF. Social Media + Society, July-September, pp. 1-11.

Tolins, J. and Samermit, P. 2016. GIFs as embodied enactments in text-mediated conversation. Research on Language and Social Interaction, 49(2), pp. 75-91.

\section{Media referenced}

Matrix.fandom.se. n.d. Spoon boy. The Matrix wiki. www.matrix.fandom.com/wiki/Sp oon_Boy [Accessed 7 April 2021].

The Matrix. 1999. There is no spoon GIF. 14 September 2016. https://media.giphy. com/media/3o6Zt0hNCfak3QCqsw/giphy.gif [Accessed 7 April 2021].

Useumorg. 2016. Nighthawks by Edward Hopper (detail and GIF). 4 April. https:// blog.useum.org/post/142231645538/nighthawks-by-edward-hopper-detail-gif-to [Accessed 7 April 2021].

Wiseau, T. 2003. The room. Los Angeles: Wiseau Films.

www.reddit.com. 2017. HIFW I go to bed every night as a single person. reddit.com. 17

March. https://www.reddit.com/r/HIFW/comments/5zwi62/hifw_i_go_to_bed_ every_night_as_a_single_person/?ref=readnext [Accessed 7 April 2021]. 